\title{
Proteome Analysis \\ of Programmed Cell Death and Defense Signaling Using the Rice Lesion Mimic Mutant cdr2
}

\author{
Hajime Tsunezuka, Masayuki Fujiwara, Tsutomu Kawasaki, and Ko Shimamoto \\ Laboratory of Plant Molecular Genetics, Nara Institute of Science and Technology, 8916-5 Takayama, Ikoma 630-0101, Japan \\ Submitted 28 May 2004. Accepted 6 September 2004.
}

\begin{abstract}
We have previously identified three lesion-mimic mutants, cell death and resistance $(c d r)$, in rice. These mutants induce a series of defense responses, including expression of defense-related genes and high accumulation of phytoalexins, indicating that the $c d r$ mutants are useful materials to study programmed cell death and defense signaling in rice. Here, we carried out a proteome analysis of the $c d r 2 \mathrm{mu}-$ tant. Total proteins prepared from the wild type and the $c d r 2$ mutant at three different stages of lesion formation were compared using two-dimensional electrophoresis. We found a total of 37 proteins that were differentially expressed between $c d r 2$ and wild type. Among them, 28 spots were up-regulated and nine were down-regulated in the $c d r 2$ mutant. All the protein spots were identified by mass spectrometric analysis. These differentially regulated proteins included defense-related proteins. In addition, 27 proteins were classified as metabolic enzymes, suggesting that the programmed cell death that occurs in the $c d r 2$ mutant is associated with active metabolic changes. Our study shows that proteome analysis is a useful approach to study programmed cell death and defense signaling in plants.
\end{abstract}

Plants have evolved defense mechanisms, including the production of phytoalexins, accumulation of antimicrobial proteins, and rearrangement of the cell wall, to protect themselves against microbial attack. One of the major defense systems is the hypersensitive response (HR), which is characterized by rapid induction of local cell death around the infection site of an avirulent pathogen and is thought to confine the pathogen by stopping it from spreading from the invasion site (Dangl et al. 1996; Greenberg 1997; Heath 2000; Lamb and Dixon 1997; Mayer et al. 2001; Pontier et al. 1998). HR cell death requires an active plant metabolism and depends on the activity of the host transcriptional machinery (Hoeberichts and Woltering 2003), including dramatic changes in calcium influx, generation of reactive oxygen species (ROS), expression of pathogenesis-related proteins, production of phytoalexins, and cross-linking of components of the cell wall. HR cell death is also accompanied by morphological changes similar to those in apoptosis in animals, such as nuclear condensation, DNA laddering, and cell shrinkage (Hoeberichts and Woltering 2003; Jacobson et al. 1997).

Many mutants that show spontaneous cell death in the absence of pathogen infection, which are called lesion mimics,

\section{H. Tsunezuka and M. Fujiwara contributed equally to this work.}

Corresponding author: K. Shimamoto; Telephone: +81 74372 5500; Fax: +81 74372 5509; E-mail: simamoto@bs.naist.jp have been identified in Arabidopsis thaliana (Balague et al. 2003; Ishikawa et al. 2001; Mach et al. 2001; Nandi et al. 2003; Pilloff et al. 2002), maize (Hu et al. 1998; Simmons et al. 1998), barley (Wolter 1993), and rice (Arase et al. 2000; Takahashi et al. 1999; Yamanouchi et al. 2002; Yin et al. 2000). Many of these mutants exhibit the expression of markers associated with defense responses, including accumulation of autofluorescent material, callose deposition, ROS production, increased expression of defense-related genes, elevated salicylic acid level, and activation of systemic acquired resistance. Therefore, defense responses may be constitutively activated in these mutants, indicating that these mutants are useful tools for understanding the comprehensive mechanism of defense responses.

Impressive achievements in genome and cDNA sequencing have yielded a wealth of information for many model organisms, including the plants Arabidopsis, and rice. However, sequence information alone is insufficient to deduce gene function. Transcriptome studies using microarray and serial analysis of gene expression technologies are powerful tools to address gene function; however, mRNA expression profiles may represent only putative function, because there is still a questionable correlation between mRNA and protein levels (Futcher et al. 1999; Gygi et al. 1999). In contrast, proteomics provides a more direct assessment of biochemical processes by monitoring the actual proteins performing the enzymatic, regulatory, and structural functions. Recent improvements of highresolution two-dimensional gel electrophoresis (2-DE) (Gorg et al. 1999; Klose and Kobalz 1995), development of protein and nucleotide databases, and methods for protein identification utilizing modern mass spectrometry, such as matrixassisted laser desorption ionization time-of-flight mass spectrometry and tandem mass spectrometry (MS/MS), have made the large-scale profiling and identification of proteins a dynamic new area of research in plant biology.

We have previously identified three lesion-mimic mutants ( $c d r 1, c d r 2$, and $C d r 3$ ) in rice (Takahashi et al. 1999). These mutants induce activation of defense-related gene expression and high accumulation of phytoalexins. Thus, the $c d r$ mutants are good materials to analyze defense-related proteins in rice. Experiments using a protein phosphatase inhibitor, calyculin A, suggested that CDR1 and CDR2 negatively regulate the phosphorylation of proteins involved in the defense-related pathway associated with NADPH oxidase (Takahashi et al. 1999). We recently identified four phosphorylated proteins in $c d r$ mutants by using the phospho-proteome method with 2 DE. One of them was prohibitin, which is known to be a chaperone in the assembly of a mitochondrial respiratory chain complex in yeast and mammalian cells (Takahashi et al. 2003). 
Until now, there have been few reports of proteome analysis that focused on the defense signaling pathway in plants (Kim et al. 2003; Peck et al. 2001). Here, we report results of a proteome analysis of the $c d r 2$ mutant to study programmed cell death and defense signaling in rice. Proteins extracted from the wild type and $c d r 2$ were compared using 2-DE and identified by the mass spectrometry system. We identified 37 proteins that were differentially expressed in the wild type and $c d r 2$. Some of them were likely associated with defense signaling. In addition, many metabolic enzymes were affected by the $c d r 2$ mutation, indicating that extensive metabolic changes are associated with programmed cell death in rice.

\section{RESULTS AND DISCUSSION}

\section{Identification of proteins up- or down-regulated in $\boldsymbol{c d r 2}$.}

The level of defense resistance to rice blast in $c d r 2$ is dependent upon lesion formation (Takahashi et al. 1999). The $c d r 2$ plant exhibits strong resistance when the lesions are fully formed. We used three different stages of leaves, based upon the degree of lesion formation: $\mathrm{NL}=$ no lesion, leaves of a 30-dayold $c d r 2$ plant without any lesions, $\mathrm{FL}=$ few lesions, leaves of a 40-day-old $c d r 2$ plant with few lesions, and ML = many lesions, leaves of a 40-day-old $c d r 2$ plant with many lesions (Fig. 1).

To identify changes in protein expression during the development of lesions, we used the total protein extracts of $c d r 2$ NL, $c d r 2-\mathrm{FL}, c d r 2-\mathrm{ML}$, and wild type as a control. The proteins extracted using a $7 \mathrm{M}$ urea and $2 \mathrm{M}$ thiourea buffer were precipitated with trichloroacetic acid (TCA) and were analyzed by 2-DE. Gel electrophoresis was performed with $\mathrm{pH}$ 4.0 to 7.0 strips and $12 \%$ sodium dodecyl sulfate (SDS)-polyacrylamide gel. Approximately 400 protein spots were detected in two-dimensional gels with Coomassie brilliant blue (CBB) staining (Fig. 2A, typical electrophoresis data, wild type and $c d r 2-\mathrm{FL})$. CBB-stained 2-DE images were acquired with an image scanner and were analyzed to identify proteins differentially expressed between the protein samples. All spots were matched by gel-to-gel comparison, using PDQuest software, and the difference in the relative abundance of each spot protein was analyzed. Some of the spots detected in the gels were not reproducible in the repetitive experiments. Therefore, they were not analyzed in further experiments. As shown in Figure $2 \mathrm{~B}$, we identified 37 proteins that were differentially expressed between $c d r 2$ and wild type. The changes of these protein levels during lesion formation were quantitatively analyzed (Fig. 2C). Among them, 28 spots were up-regulated and nine were down-regulated during the lesion formation of $c d r 2$ (Fig. 3). These proteins showed $>3.0$-fold changes in three or more replicate gels. All spots were excised from the gels of wild type, $c d r 2-\mathrm{NL}, c d r 2-\mathrm{FL}$, and $c d r 2-\mathrm{ML}$, and the gel pieces were digested with trypsin and subjected to tandem mass spectrometry analysis. These MS/MS data from collision-induced ion fragments were searched against the equivalent theoretical masses derived from the National Center for Biotechnology Information (NCBI) nonredundant protein database, using Mascot software (Perkins et al. 1999). We identified all of them as listed in Table 1. The identified proteins were categorized into three classes based upon their expression pattern and four classes based upon their putative functions (Fig. 3A and B; Table 1). The protein levels of classes I and II were increased and reduced, respectively, along with lesion formation. In class III, the levels of protein were greater in the NL stage and gradually decreased at later stages.

\section{Defense-related proteins.}

Five proteins (spots 1, 2, 14, 16, and 21) of class I were abundantly accumulated in the ML stage. Two proteins, pro- benazole-induced protein (PBZ 1) (spot 1) and caffeic acid 3$O$-methyltransferase (COMT) (spot 2), have already been reported as defense-related proteins. The $P B Z 1$ gene encodes an intracellular pathogenesis-related protein and is activated by treatment by probenazole, which is an effective inducer of host resistance against blast (Midoh and Iwata 1996). A high accumulation of PBZ 1 protein was consistent with our previous observation that $P B Z 1$ gene expression is highly induced in lesion-mimic mutants, including $c d r 2$ (Takahashi et al. 1999). COMT, which is known as an enzyme involved in the phenylpropanoid pathway, is strongly induced after infection of pathogens and fungal-elicitor treatment (Dumas et al. 1988; Jaeck et al. 1992; Pellegrini et al. 1993, 1994). The phenylpropanoid components form a large class of secondary metabolites in plants as part of their antimicrobial defense tools. For example, flavonoids, isoflavonoids, stibenes, monolignols, and lignins serve as inducible phytoalexins or preformed phytoanticipins in many plant species (Dixon 2001; Dixon et al. 2002), and the phenylpropanoid polymer can act as an inducible physical barrier against pathogen ingress (Mitchell et al. 1999).

We have identified two different ROS scavengers, glutathione $S$-transferase (GST, spot 5) and superoxide dismutase (SOD, spot 4). Interestingly, the levels of these proteins were opposite at the FL and ML stages; the level of GST was high in the FL stage and low at the ML stage, whereas SOD was down-regulated at the FL stage and up-regulated at the ML stage. Although both proteins are known to reduce ROS induced by biotic and abiotic stresses (Alvarez et al. 1998; Edwards et al. 2000), these proteins likely function at different stages of lesion formation. In addition, it is shown that spreading of lesions in the Arabidpsis lsd 1 mutant is caused by the lack of up-regulation of SOD, which may result in the accumulation of superoxide (Kliebenstein et al. 1999). Thus, down-regulation of SOD at the FL stage suggests that an accumulation of superoxide may be necessary to establish the lesion phenotype.

\section{Molecular chaperones.}

We identified four molecular chaperone proteins (spots 6, 7, 8 , and 31) that were up-regulated during the appearance of cell death lesion. Heat shock protein (Hsp) 70 and DnaK-type molecular chaperone BiP are members of the Hsp70/DnaK family, and chaperonin-60 and Rubisco subunit binding protein are members of the Hsp60/GroEL family (Fink 1999). These proteins likely play a role in the stabilization and facilitation of refolding of proteins that have been denatured during exposure to various stresses (Bukau and Horwich 1998; Fink 1999). Hsp70 and Hsp60 have been found to functionally cooperate

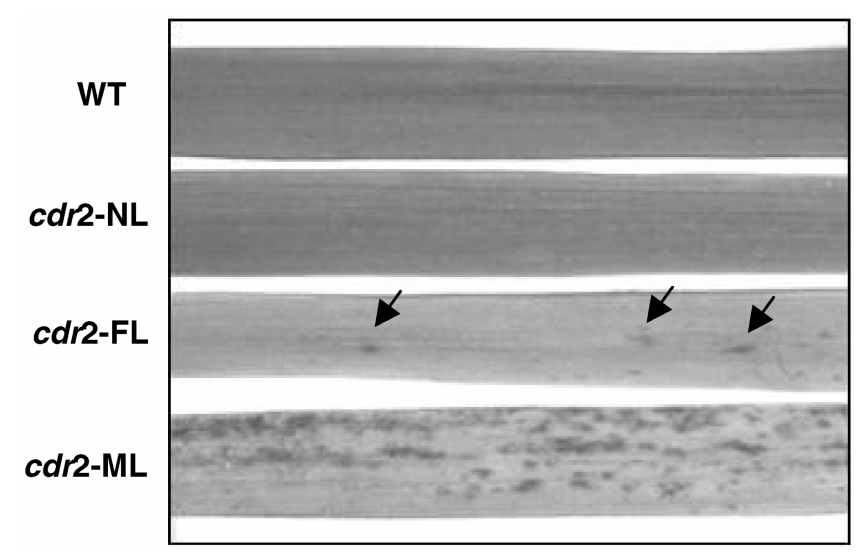

Fig. 1. Lesion-mimic phenotypes of the $c d r 2$ mutants. NL $=$ leaves of 30 day-old $c d r 2$ plant without any lesions, $\mathrm{FL}=$ leaves of a 40 -day-old $c d r 2$ plant with few lesions, and ML $=$ leaves of a 40-day-old $c d r 2$ plant with many lesions. 
in vitro and are regulated for the maintenance of proteins in cell (Langer et al. 1992). Additionally, in Escherichia coli, the DnaK and GroE systems cooperate for the preservation of aggregation in the folding of ferredoxin-NADP reductase (FNR) (Dionisi et al. 1998). FNR is known to be a member of ubiquitous flavoenzymes involved in oxidoreductive pathways in bacteria (Arakaki et al. 1997). Our data showed that FNR (spot 33) was up-regulated at the ML stage, suggesting that Hsp70 and Hsp60 may cooperate for pre-FNR processing in rice.

\section{Metabolic enzymes.}

The differentially expressed proteins contained 27 metabolic enzymes. $S$-adenosylmethionine (SAM) synthase (spot 3 ) catalyzes the conversion of L-methionine and ATP into SAM. SAM serves as a precursor of the plant hormone ethylene, which is induced by wounding, drought, and pathogen invasion (Arimura et al. 2002). SAM synthase accumulated during lesion formation in $c d r 2$, suggesting that ethylene is involved in cell death. This is consistent with the fact that ethylene regu-

A

(k Da)

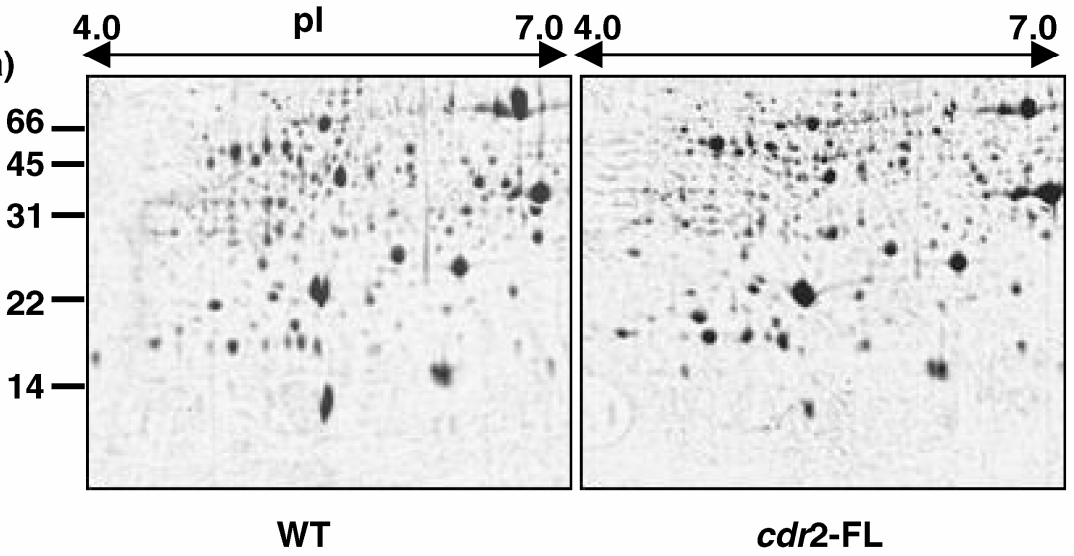

B

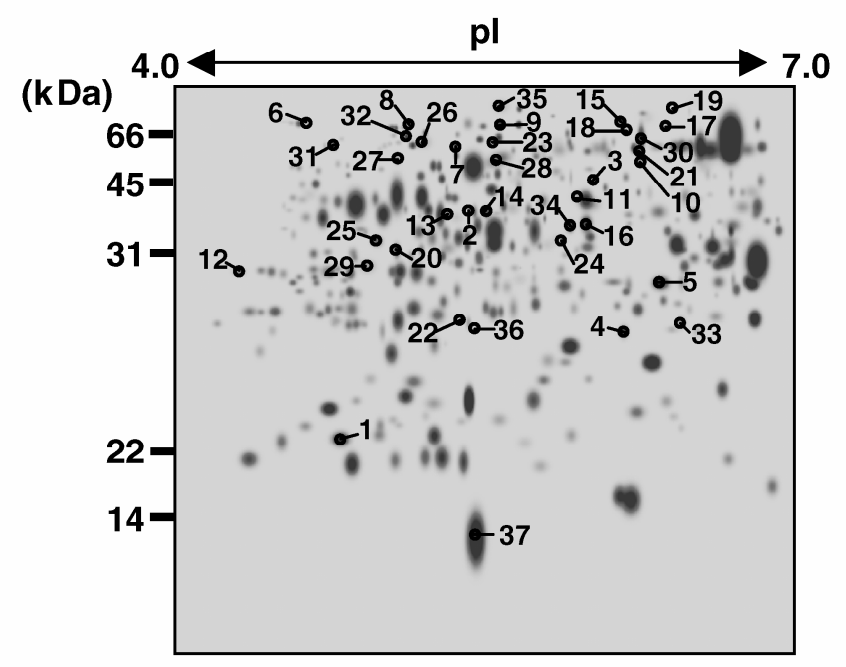

C

Spot No. 8
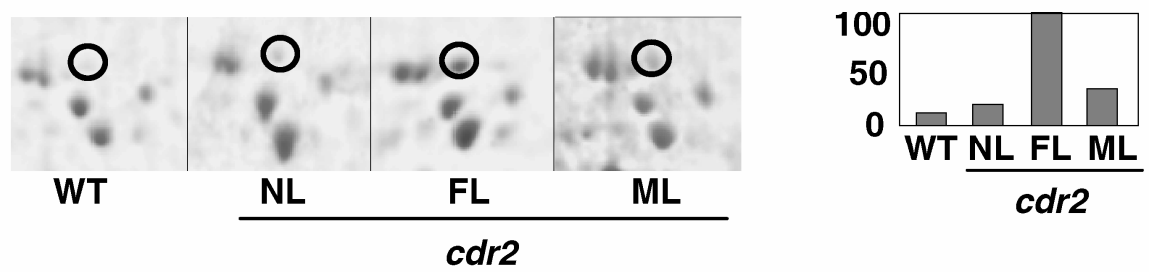

Fig. 2. Two-dimensional electrophoresis maps of wild type and $c d r 2$ mutants. A, Comparison of spot patterns derived from wild type and leaves of 30 -dayold $c d r 2$ poant with few lesions ( $c d r 2-$ FL). Isoelectric focusing was performed with 13-cm IPG strips, pH 4 to 7 . After separation with sodium dodecyl sulfate-polyacrylamide gel electrophoresis (12\% acrylamide gel), the gels were stained with CBB. Image analysis was performed using PDQuest. B, Standard image constructed on the PDQuest software. Proteins with a spot number on the gels have more than three times higher or lower levels in wild type than those in $c d r 2$ mutants. C, Quantitative analysis of spot 8 during lesion formation. Spot 8 was encircled on each gel. These spots were quantified using the PDQuest software. The highest value was set equal to 100. 


\section{Class I}

1. Probenazole-induced protein

2. Caffeic acid 3-0-methyltransferase

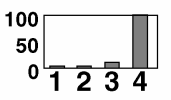

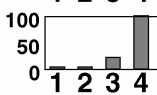

3. S-adenosylmethionine synthetase $2 \underset{50}{100}$

5. Glutathione S-transferase II

6. putative heat shock protein $\mathbf{7 0}$

7. Mitochondrial chaperonin-60

8. DnaK-type molecular chaperone BiP

10. Putative cytosolic 6phosphogluconate dehydrogenase

11. Putative glyceraldehyde-3phosphate dehydrogenase

13. Phosphoglucomutase

14. Glutamine synthetase

15. NADP-dependent malic enzyme

\section{Class II}

4. Probable superoxide dismutase 2 precursor

12. Phosphoglycerate kinase

17. Putative oxalyl-CoA decarboxylase

20. Putative thiamine biosynthesis protein

25. Putative fructokinase II

26. Vacuolar ATP synthase catalytic subunit A

29. Sedoheptulose-1,7bisphosphatase precursor

36. $20 \mathrm{~S}$ proteasome subunit alpha type 2

37. Ribulose 1,5-bisphosphate carboxylase/oxygenase large chain
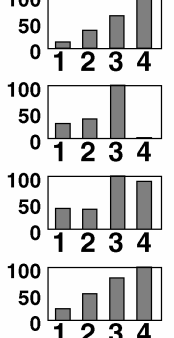

04234

50

012324

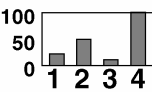

1000

$0 \frac{12}{12} 34$

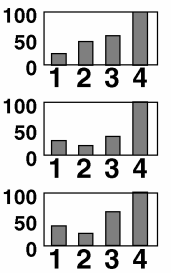

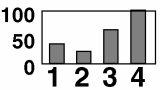

35. ATP-dependent Clp protease

\section{C}

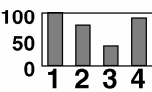

01234

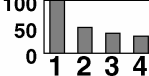

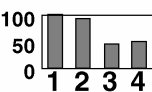

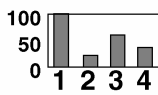

\begin{tabular}{r|r|ll}
100 & & & \\
50 & & & \\
0 & 1 & 2 & 34
\end{tabular}

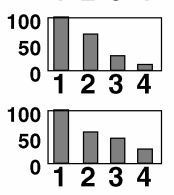

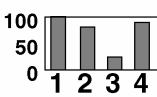

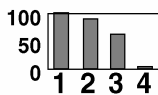

22. Ferritin

24. Putative isoflavone reductase homolog IRL

27. Putative $\mathbf{H + - t r a n s p o r t i n g ~ A T P ~}$ synthase

28. ATP synthase beta subunit

33. Ferredoxin-NADP reductase factor

\section{Class III}

9. Putative transketolase

19. Putative methionine synthase
16. Cytoplasmic malate dehydrogenase

21. Aldehyde dehydrogenase

23. Methylenetetrahydrofolate reductase $\begin{gathered}50 \\ 0\end{gathered}$

31. Putative Rubisco subunit binding protein alpha subunit precursor

34. Photosystem Ilstability/assembly
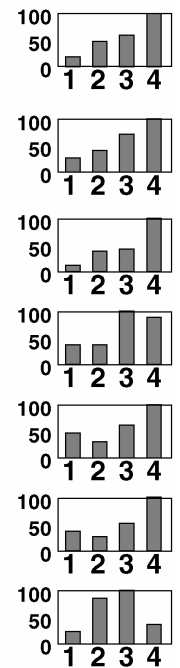

18. Putative glycine dehydrogenase

30. ATP synthase CF1 alpha chain

32. FtsH-like protein Pftf precursor
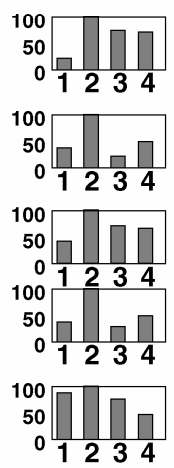

Fig. 3. Classification of the identified proteins based upon expression pattern. The identified proteins were categorized into three classes; A, Class I or B, Class II were increased or reduced, respectively, along with lesion formation, and $\mathbf{C}$, Class III was increased in the stage of NL (no lesions) and gradually decreased at later stages. 1, wild type; 2, $c d r 2$-NL; 3, $c d r 2$-FL (few lesions); 4, $c d r 2$-ML (many lesions). The highest value was set equal to 100. 
lates ROS production and spreading of cell death in the etol and eto 3 mutants that overproduce ethylene in Arabidopsis (Wang et al. 2002).

Glyceraldehydes-3-phosphate dehydrogenase (GAPDH) is a glycolytic enzyme. However, this protein also possesses a number of secondary functions including a cellular protein kinase, an mRNA binding protein for translation regulation, and a DNA repair enzyme with uracil DNA glycosylate activity (Meyer-Siegler et al. 1991). Recently, GAPDH has been shown to function as a positive mediator for apoptotic cell death in animals (Dastoor and Dreyer 2001). As shown in Figure 3 the level of GAPDH protein (spot 11) increased during the lesion formation of $c d r 2$, suggesting that GAPDH may stimulate cell death in rice.

In this work, we identified three enzymes, putative transketolase, putative cytosolic 6-phosphogluconate dehydrogenase, and sedoheptulose-1,7-bisphosphatase precursor, involved in pentose phosphate pathway. Among them, 6-phosphogluconate dehydrogenase provides NADPH, which is required for the activity of plasma membrane NADPH oxidase to produce ROS during a defense response (de Pinto et al. 2002). The protein level of 6-phosphogluconate dehydrogenase (spot 10) was upregulated at the ML stage. Because the nature of $c d r 2$ mutation is assumed to be associated with the regulation of NADPH oxidase activity (Takahashi et al. 1999), it is possible that the up-regulation of 6-phosphogluconate dehydrogenase contributes to the activation of NADPH oxidase in lesion formation.

Aldehyde dehydrogenase (ALDH; spot 21) was highly accumulated in the ML stage. ALDH catalyzes the oxidation of various toxic aldehydes to carboxylic acids (Liu and Schnable 2002; Nakazono et al. 2000; Sunkar et al. 2003). A well-studied ALDH is betaine aldehyde dehydrogenase, which is induced in response to osmotic stress (Chen and Murata 2002). Overexpression of Arabidopsis ALDH results in the reduction of oxidative stress by scavenging toxic aldehydes (Sunkar et al. 2003). Thus, the up-regulation of ALDH in $c d r 2$ is likely one of the responses against oxidative stress, which occurs in lesion formation.

Ribulose-1,5-bisphosphate carboxylase (Rubisco; spot 37) was down-regulated during lesion formation. The spot was de-

Table 1. List of identification proteins

\begin{tabular}{|c|c|c|c|c|c|c|c|c|}
\hline Protein type & $\begin{array}{l}\text { Spot } \\
\text { no. }\end{array}$ & Homologous protein & Source & Accession & Class & $\begin{array}{c}\text { Mascot } \\
\text { score }\end{array}$ & $\begin{array}{c}\text { No. of } \\
\text { peptide }\end{array}$ & $\begin{array}{c}\text { Coverage } \\
(\%)\end{array}$ \\
\hline \multirow[t]{5}{*}{ Defense related } & 1 & Probenazole-induced protein (PBZ1) & Oryza sativa & gi 7442204 & I & 914 & 7 & 38 \\
\hline & 2 & Caffeic acid 3-O-methyltransferase & Oryza sativa & AK061859 & I & 185 & 4 & 12 \\
\hline & 4 & Probable superoxide dismutase (EC & & & & & & \\
\hline & & 1.15.1.1) (Mn) 2 precursor $\mathrm{Mn}-\mathrm{SOD}$ & Oryza sativa & gi 7433347 & II & 268 & 4 & 28 \\
\hline & 5 & Glutathione $S$-transferase ? (GST) & Oryza sativa & gi|3746581 & I & 243 & 4 & 22 \\
\hline \multirow[t]{3}{*}{ Chaperone } & 6 & Putative heat shock protein 70 (HSP70) & Oryza sativa & AK060410 & I & 399 & 8 & 16 \\
\hline & 7 & Mitochondrial chaperonin-60 & Oryza sativa & gi|22758324 & I & 304 & 7 & 15 \\
\hline & 8 & DnaK-type molecular chaperone BiP & Oryza sativa & gi|7441868 & I & 535 & 8 & 16 \\
\hline \multirow[t]{32}{*}{ Metabolism related } & 3 & $S$-adenosylmethionine synthetase 2 & Oryza sativa & gi|3024122 & I & 396 & 7 & 22 \\
\hline & 9 & Putative transketolase & Oryza sativa & gi 11875148 & III & 626 & 14 & 18 \\
\hline & 10 & Putative cytosolic 6-phosphogluconate & & & & & & \\
\hline & & dehydrogenase & Oryza sativa & gi|7363280 & I & 162 & 3 & 8 \\
\hline & 11 & $\begin{array}{l}\text { Putative glyceraldehyde-3-phosphate } \\
\text { dehydrogenase }\end{array}$ & & gi|23306126 & & 467 & & \\
\hline & 12 & $\begin{array}{l}\text { dehydrogenase } \\
\text { Phosphoglycerate kinase }\end{array}$ & $\begin{array}{l}\text { Oryza sativa } \\
\text { Oryza sativa }\end{array}$ & $\begin{array}{l}\text { gi| } 23306126 \\
\text { gi } 50905557\end{array}$ & $\begin{array}{l}\text { I } \\
\text { II }\end{array}$ & $\begin{array}{l}467 \\
226\end{array}$ & $\begin{array}{l}7 \\
4\end{array}$ & $\begin{array}{l}20 \\
18\end{array}$ \\
\hline & 13 & $\begin{array}{l}\text { Phosphoglycerate Kinase } \\
\text { Phosphoglucomutase }\end{array}$ & Oryza sativa & gi| 13324798 & I & 675 & $\begin{array}{l}4 \\
6\end{array}$ & $\begin{array}{l}18 \\
12\end{array}$ \\
\hline & 14 & Glutamine synthetase shoot isozyme & Oryza sativa & gi|121349 & I & 494 & 4 & 9 \\
\hline & 15 & NADP dependent malic enzyme & Oryza sativa & gi 12082337 & I & 236 & 5 & 12 \\
\hline & 16 & Cytoplasmic malate dehydrogenase & Oryza sativa & AC037425 & I & 642 & 9 & 14 \\
\hline & 17 & Putative oxalyl-CoA decarboxylase & Oryza sativa & AP003054 & II & 320 & 8 & 19 \\
\hline & 18 & Putative glycine dehydrogenase & Oryza sativa & gi|13366201 & III & 280 & 6 & 24 \\
\hline & 19 & Putative methionine synthase & Oryza sativa & AK067726 & III & 146 & 2 & 2 \\
\hline & 20 & Putative thiamine biosynthesis protein & Oryza sativa & dbj|BAC45141.1| & II & 175 & 4 & 19 \\
\hline & 21 & Aldehyde dehydrogenase & Oryza sativa & gi 8163730 & I & 630 & 9 & 19 \\
\hline & 22 & Ferritin & Oryza sativa & gi|14091661 & I & 380 & 6 & 23 \\
\hline & 23 & Methylenetetrahydrofolate reductase & & & & & & \\
\hline & & (MTHFR) & Oryza sativa & AK062082 & I & 174 & 5 & 12 \\
\hline & 24 & Putative isoflavone reductase homolog IRL & Oryza sativa & gi|10945249 & I & 238 & 6 & 22 \\
\hline & 25 & Putative fructokinase? & Oryza sativa & gi|16566704 & II & 327 & 6 & 22 \\
\hline & 26 & Vacuolar ATP synthase catalytic subunit A & & & & & & \\
\hline & & (V-ATPase A subunit) & Oryza sativa & gi|1352830 & II & 262 & 5 & 11 \\
\hline & 27 & Putative H+transporting ATP synthase & Oryza sativa & gi|13366196 & I & 571 & 5 & 8 \\
\hline & 28 & ATP synthase beta subunit & Oryza sativa & gi|21684925 & I & 367 & 7 & 16 \\
\hline & 29 & Sedoheptulose-1,7-bisphosphatase precursor & Oryza sativa & gi|27804768 & II & 411 & 6 & 20 \\
\hline & 30 & ATP synthase CF1 alpha chain & Oryza sativa & NC_001320 & III & 322 & 12 & 26 \\
\hline & 31 & Rubisco subunit binding-protein alpha & & & & & & \\
\hline & & subunit, chloroplast precursor & Oryza sativ & AK061410 & I & 394 & 7 & 14 \\
\hline & 33 & Ferredoxin-NADP reductase & Oryza sativa & gi|729478 & I & 237 & 9 & 19 \\
\hline & 34 & Photosystem II stability/assembly factor & Arabidopsis & & & & & \\
\hline & & HCF136 & thaliana & NM_122218 & I & 212 & 5 & 11 \\
\hline & 37 & $\begin{array}{l}\text { Ribulose 1,5-bisphosphate carboxylase/ } \\
\text { oxygenase large chain (fragment) }\end{array}$ & Oryza sativ & gi|11466795 & II & 78 & 2 & 6 \\
\hline \multirow{4}{*}{$\begin{array}{l}\text { Proteasome and } \\
\text { protease }\end{array}$} & 32 & Putative ftsH chloroplast protease & & & & & & \\
\hline & & & Oryza sativa & AK061771 & III & 439 & 7 & 16 \\
\hline & 35 & ATP-dependent Clp protease & Oryza sativa & gi|32489942 & I & 366 & 7 & 8 \\
\hline & 36 & Proteasome subunit alpha type 2 & Oryza sativa & gi|12229921 & II & 320 & 6 & 25 \\
\hline
\end{tabular}


tected at a lower molecular mass position (16 kDa) compared with the expected size (53 kDa) of Rubisco. This may be possibly explained by the observation that oxidative stress induces fragmentation of the Rubisco protein in vitro (Ishida et al. 1997, 1999).

\section{Proteasome and protease.}

We identified 20S proteasome subunit, alpha type 2 (spot 36), which was down-regulated in the initial stage of lesion formation. The $20 \mathrm{~S}$ proteasome is one of the components of $26 \mathrm{~S}$ proteasome involved in the recognition and degradation of ubiquitinated protein (Grune 2000). The ubiquitin/26S proteasome pathway has important roles in plant growth, development, and defense through protein degradation (Sullivan et al. 2003). Recently, it has been reported that the inhibition of proteasome activities results in the activation of programmed cell death in plants (Moonil et al. 2003), which is coincident with the down-regulation of a $20 \mathrm{~S}$ proteasome subunit during the lesion formation of $c d r 2$.

FtsH protease (spot 32) and Clp protease (spot 35) are known to be chloroplastic proteases involved in the removal of oxidatively damaged proteins and settlement of quantity of certain chloroplast proteins in response to a large variety of environmental conditions (Adam and Clarke 2002). The level of tobacco chloroplastic FtsH protease is reduced in Tobacco mosaic virus-infected leaves before the HR lesion appears, which results in the acceleration of cell death (Seo et al. 2000). The phenomenon is consistent with the fact that rice FtsH protease (spot 32) decreased during the lesion formation of $c d r 2$. Clp protease (spot 35), an ATP-dependent serine protease, was upregulated in the $c d r 2$ mutant. Clp protease has been reported to be increased at both the mRNA and protein levels by high light, cold, and ozone (Agrawal et al. 2002; Zheng et al. 2002). Therefore, clp protease is likely a positive factor to stress responses in plants.

In the present work, we have found a total of 37 proteins that were differentially expressed between the wild type and $c d r 2$. All of them were identified by mass spectrometric analysis. Thus, this type of proteome analysis is shown to be useful for the identification of proteins that have important functions. Among 37 proteins that we have identified, four are likely to be defense-related. Interestingly, many metabolic enzymes were changed during lesion formation. These results suggested that the programmed cell death occurring in the $c d r 2$ mutant is accompanied with active metabolic changes. The comprehensive proteome analysis of defense-related mutants may provide new insights to understand signaling networks involved in programmed cell death and defense signaling in plants.

\section{MATERIALS AND METHODS}

\section{Plant material.}

The rice cultivar Kinmaze (wild type) and the $c d r 2$ mutant were used in this work. The plants were grown in a greenhouse, and their leaves were harvested at three different stages according to the levels of lesion formation.

\section{Protein extraction.}

Frozen rice leaves were ground in liquid nitrogen. The resultant powder was suspended in an extraction buffer $(7 \mathrm{M}$ urea/2 M thiourea; 4\% (wt/vol) 3-[(3-cholamidopropyl) dimethylammonio]-1-propane-sulfonate (CHAPS); $20 \mathrm{mM}$ dithiothreitol (DTT); 2\% (vol/vol) immobilized $\mathrm{pH}$ gradient (IPG) buffer, $\mathrm{pH} 3$ to 10 . Crude homogenates were centrifuged at $4^{\circ} \mathrm{C}(9,000 \times g$ for $30 \mathrm{~min})$. The supernatants were precipitated by $10 \%$ TCA for $1 \mathrm{~h}$ at $-30^{\circ} \mathrm{C}$, followed by centrifugation at $13,000 \times g$ for $30 \mathrm{~min}$. The pellets were washed twice with cold-acetone and were allowed to air dry. The dried samples were resuspended with extraction buffer and were kept frozen at $-80^{\circ} \mathrm{C}$. Protein contents were determined by the Bradford (1976) method using bovine serum albumin as a standard.

\section{2-DE and image analysis.}

For analytical separations, precast $13-\mathrm{cm}$ immobilized $\mathrm{pH}$ gradient strips ( $\mathrm{pH} 4$ to 7, immobiline DryStrips; Amersham Biosciences, Piscataway, NJ, U.S.A.) were rehydrated overnight with $1.2 \mathrm{mg}$ of sample proteins and $250 \mu \mathrm{l}$ of a rehydration buffer ( $7 \mathrm{M}$ urea/2 M thiourea; $4 \%$ (wt/vol), CHAPS; $20 \mathrm{mM}$ DTT; $2 \%$ (vol/vol) IPG buffer, $\mathrm{pH} 4$ to 7; bromophenol blue). Isoelectric focusing was performed for $36 \mathrm{kVh}$ at $20^{\circ} \mathrm{C}$ with a Multiphor II unit (Amersham Biosciences). The strips were placed in a reduction buffer (1\% DTT, $6 \mathrm{M}$ urea, $2 \%$ SDS, 30\% glycerol, $50 \mathrm{mM}$ Tris- $\mathrm{HCl}, \mathrm{pH} 8.8$ ) for $20 \mathrm{~min}$ with gentle shaking. The strips were then transferred to an alkylation buffer $(2.5 \%$ iodoacetamide, $6 \mathrm{M}$ urea, $2 \%$ SDS, $30 \%$ glycerol, $50 \mathrm{mM}$ Tris- $\mathrm{HCl}, \mathrm{pH} 8.8$ ) and were shaken for 20 min before being placed on a $12 \%$ polyacrylamide gel slab $(160 \times 160 \times 1.0 \mathrm{~mm})$. Separation in the second dimension was carried out using a Tris-glycine buffer ( $25 \mathrm{mM}$ Tris, 192 $\mathrm{mM}$ glycine, $0.1 \%$ SDS) at a current setting of $10 \mathrm{~mA} / \mathrm{gel}$.

The 2-DE gels were stained with Coomassie brilliant blue R-350 (Amersham Biosciences). 2-DE images were acquired by scanning with a scanner (GS-800 calibrated imaging densitometer; Bio-Rad, Hercules, CA, U.S.A.). Noise reduction, background subtraction, spot detection, quantification, gel-togel matching, and differential protein display analysis were carried out using the PDQuest software (Bio-Rad). Intensities of individual spots were normalized based upon the total density of all spots detected in each gel and compared between gels. Selected spots were excised and stored at $4{ }^{\circ} \mathrm{C}$ in deionized water.

\section{Protein identification.}

Gel pieces excised from the CBB-stained gels were destained with $30 \%$ acetonitrile (Wako, Osaka, Japan), were washed with $100 \%$ of acetonitrile, and were dried in a vacuum concentrator. The dried gel pieces were absorbed with $2 \mu$ l of tryp$\sin / 50 \mathrm{mM}$ ammonium bicarbonate $(0.5 \mu \mathrm{g} / \mu \mathrm{l})$ (Promega, Madison, WI, U.S.A.) (Shevchenko et al. 1996). After the digestion reaction at $37^{\circ} \mathrm{C}$, the digested peptides were extracted with 5\% formic acid and 50\% acetonitrile. Trypsin-digested peptides were loaded on the column (PEPMAPC18, $5 \mu \mathrm{m}, 75$ $\mu \mathrm{m}$ internal diameter, $15 \mathrm{~cm}$; Dionex, Sunnyvale, CA, U.S.A.) using the CapLC system (Waters, Wythenshawe, U.K.). Buffers were $0.1 \% \mathrm{HCOOH}$ in water (A) and $0.1 \% \mathrm{HCOOH}$ in acetonitrile (B). A linear gradient from 5 to $45 \%$ B for 25 min was applied, and peptides eluted from the column were introduced directly into a Q-tof mass spectrometer (Waters) with a flow rate of $100 \mathrm{nl} / \mathrm{min}$. Ionization was performed with a PicoTip nanospray source (New Objective; Cambridge, MA, U.S.A.). Masses of precursor ions were scanned from m/z 400 to 1,500; scan time was $1.0 \mathrm{~s}$. The collision voltage was 20 to $40 \mathrm{~V}$, depending on the precursor mass. MS/MS spectrums were subjected to the Mascot server against a protein database from the NCBI. Mascot search parameters included digestion by trypsin with allowance of one missed cleavage, peptide tolerance \pm 0.2 $\mathrm{Da}$, and MS/MS tolerance $\pm 0.2 \mathrm{Da}$.

\section{ACKNOWLEDGMENTS}

We thank M. Kuwano (Nara Institute of Science and Technology) for the identification of some proteins by LCQ ion trap mass spectrometer (Finnigan MAT, San Jose, CA, U.S.A.) 


\section{LITERATURE CITED}

Adam, Z., and Clarke, A. K. 2002. Cutting edge of chloroplast proteolysis. Trend Plant Sci. 7:451-456.

Agrawal, G., Rakwal, R., Yonekura, M., Kubo, A., and Saji, H. 2002. Proteome analysis of differentially displayed proteins as a tool for investigating ozone stress in rice (Oryza sativa L.) seedlings. Proteomics 2:947-959.

Alvarez, M., Pennell, R., Meijer, P., Ishikawa, A., Dixon, R., and Lamb, C. 1998. Reactive oxygen intermediates mediate a systemic signal network in the establishment of plant immunity. Cell 92:773-784.

Arakaki, A., Ceccarelli, E., and Carrillo, N. 1997. Plant-type ferredoxinNADP+ reductase : A basal structural framework and a multiplicity of functions. FASEB (Fed. Am. Soc. Exp. Biol.) J. 11:133-140.

Arase, S., Zhao, C.-M., Akimitsu, K., Yamamoto, M., and Ichill, M. 2000. A recessive lesion mimic mutant of rice with elevated resistance to fungal pathogens. J. Gen. Plant Pathol. 66:109-116.

Arimura, G.-I., Ozawa, R., Nishioka, T., Boland, W., Koch, T., Kuhnemann, F., and Takabayashi, J. 2002. Herbivore-induced volatiles induce the emission of ethylene in neighboring lima bean plants. Plant J. 29:87-98.

Balague, C., Lin, B., Alcon, C., Flottes, G., Malmstrom, S., Kohler, C., Neuhaus, G., Pelletier, G., Gaymard, F., and Roby, D. 2003. HLM1, an essential signaling component in the hypersensitive response, is a member of the cyclic nucleotide-gated channel ion channel family. Plant Cell 15:365-379.

Bradford, M. 1976. A rapid and sensitive method for the quantitation of microgram quantities of protein using the principle of protein dye binding. Anal. Biochem. 72:248-254.

Bukau, B., and Horwich, A. L. 1998. The Hsp70 and Hsp60 chaperone machines. Cell 92:351-366.

Chen, T. H. H., and Murata, N. 2002. Enhancement of tolerance of abiotic stress by metabolic engineering of betaines and other compatible solutes. Curr. Opin. Plant Biol. 5:250-257.

Dangl, J., Dietrich, R., and Richberg, M. 1996. Death don't have no mercy: Cell death programs in plant-microbe interactions. Plant Cell. 8:1793-1807

Dastoor, Z., and Dreyer, J. 2001. Potential role of nuclear translocation of glyceraldehyde-3-phosphate dehydrogenase in apoptosis and oxidative stress. J. Cell Sci. 114:1643-1653.

de Pinto, M. C., Tommasi, F., and De Gara, L. 2002. Changes in the antioxidant systems as part of the signaling pathway responsible for the programmed cell death activated by nitric oxide and reactive oxygen species in tobacco Bright-Yellow 2 cells. Plant Physiol. 130:698-708.

Dionisi, H., Checa, S., Krapp, A., Arakaki, A., Ceccarelli, E., Carrillo, N., and Viale, A. 1998. Cooperation of the DnaK and GroE chaperone systems in the folding pathway of plant ferredoxin-NADP+ reductase expressed in Escherichia coli. Eur. J. Biochem. 251:724-728.

Dixon, R. 2001. Natural products and plant disease resistance. Nature. 411:843-847

Dixon, R. A., Achnine, L., Kota, P., Liu, C.-J., Reddy, M. S. S., and Wang, L. 2002. The phenylpropanoid pathway and plant defence-A genomics perspective. Mol. Plant Pathol. 3:371-390.

Dumas, B., van Doorsselaere, J., Geoffrey, P., and Fritig, B. 1988. Purification of tobacco $O$-methyltransferases by affinity chromatography and estimation of the rate of synthesis of the enzyme during hypersensitive reaction to virus infection. Planta 176:36-41.

Edwards, R., Dixon, D. P., and Walbot, V. 2000. Plant glutathione $S$-transferases: Enzymes with multiple functions in sickness and in health. Trend Plant Sci. 5:193-198.

Fink, A. L. 1999. Chaperone-mediated protein folding. Physiol. Rev. 79:425-449.

Futcher, B., Latter, G. I., Monardo, P., McLaughlin, C. S., and Garrels, J. I. 1999. A sampling of the yeast proteome. Mol. Cell. Biol. 19:7357-7368.

Gorg, A., Obermaier, C., Boguth, G., and Weiss, W. 1999. Recent developments in two-dimensional gel electrophoresis with immobilized $\mathrm{pH}$ gradients: Wide $\mathrm{pH}$ gradients up to $\mathrm{pH} 12$, longer separation distances and simplified procedures. Electrophoresis 20:712-717.

Greenberg, J. T. 1997. Programmed cell death in plant-pathogen interactions. Annu. Rev. Plant Physiol. Plant Mol. Biol. 48:525-545.

Grune, T. 2000. Oxidative stress, aging and the proteasomal system. Biogerontology 1:31-40.

Gygi, S. P., Rochon, Y., Franza, B. R., and Aebersold, R. 1999. Correlation between protein and mRNA abundance in yeast. Mol. Cell. Biol. 19:1720-1730.

Heath, M. 2000. Hypersensitive response-related death. Plant Mol. Biol. 44:321-334

Hoeberichts, F., and Woltering, E. 2003. Multiple mediators of plant programmed cell death: Interplay of conserved cell death mechanisms and plant-specific regulators. Bioassays 25:47-57.
Hu, G., Yalpani, N., Briggs, S. P., and Johal, G. S. 1998. A porphyrin pathway impairment is responsible for the phenotype of a dominant disease lesion mimic mutant of maize. Plant Cell 10:1095-1106.

Ishida, H., Nishimori, Y., Sugisawa, M., Makino, A., and Mae, T. 1997. The large subunit of ribulose-1,5-bisphosphate carboxylase/oxygenase is fragmented into $37-\mathrm{kDa}$ and $16-\mathrm{kDa}$ polypeptides by active oxygen in the lysates of chloroplasts from primary leaves of wheat. Plant Cell Physiol. 38:471-479.

Ishida, H., Makino, A., and Mae, T. 1999. Fragmentation of the large subunit of ribulose-1,5-bisphosphate carboxylase by reactive oxygen species occurs near Gly-329. J. Biol. Chem. 274:5222-5226.

Ishikawa, A., Okamoto, H., Iwasaki, Y., and Asahi, T. 2001. A deficiency of coproporphyrinogen III oxidase causes lesion formation in Arabidopsis. Plant J. 27:89-99.

Jacobson, M., Weil, M., and Raff, M. 1997. Programmed cell death in animal development. Cell 88:347-354.

Jaeck, E., Dumas, B., Geoffroy, P., Favet, N., Inze, D., Van Montagu, M., Fritig, B., and Legrand, M. 1992. Regulation of enzymes involved in lignin biosynthesis: induction of $O$-methyltransferase mRNAs during the hypersensitive reaction of tobacco to Tobacco mosaic virus. Mol. Plant-Microbe Interact. 5:294-300.

Kim, S., Cho, K., Yu, S., Kim, S., Hong, J., Han, C., Bae, D., Nam, M., and Kang, K. 2003. Proteomic analysis of differentially expressed proteins induced by rice blast fungus and elicitor in suspension-cultured rice cells. Proteomics 3:2368-2378.

Kliebenstein, D. J., Dietrich R. A., Martin, A. C., Last, R. L., and Dangl, J. L., 1999. LSD1 regulates salicylic acid induction of copper zinc superoxide dismutase in Arabidopsis thaliana. Mol. Plant-Microbe Interact. 12:1022-1026.

Klose, J., and Kobalz, U. 1995. Two-dimensional electrophoresis of proteins: An updated protocol and implications for a functional analysis of the genome. Electrophoresis 16:1034-1059.

Lamb, C., and Dixon, R. A. 1997. The oxidative burst in plant disease resistance. Ann. Rev. Plant Physiol. Plant Mol. Biol. 48:251-275.

Langer, T., Lu, C., Echols, H., Flanagan, J., Hayer, M., and Hartl, F. 1992. Successive action of DnaK, DnaJ and GroEL along the pathway of chaperone-mediated protein folding. Nature 356:683-689.

Liu, F., and Schnable, P. 2002. Functional specialization of maize mitochondrial aldehyde dehydrogenases. Plant Physiol. 130:1657-1674.

Mach, J. M., Castillo, A. R., Hoogstraten, R., and Greenberg, J. T. 2001. The Arabidopsis-accelerated cell death gene ACD2 encodes red chlorophyll catabolite reductase and suppresses the spread of disease symptoms. Proc. Natl. Acad. Sci. U.S.A. 98:771-776.

Mayer, A. M., Staples, R. C., and Gil-ad, N. L. 2001. Mechanisms of survival of necrotrophic fungal plant pathogens in hosts expressing the hypersensitive response. Phytochemistry 58:33-41.

Meyer-Siegler, K., Mauro, D., Seal, G., Wurzer, J., deRiel, J., and Sirover, M. 1991. A human nuclear uracil DNA glycosylase is the 37-kDa subunit of glyceraldehyde-3-phosphate dehydrogenase. Proc. Natl. Acad. Sci. U.S.A. 88:8460-8464

Midoh, N., and Iwata, M. 1996. Cloning and characterization of a probenazole-inducible gene for an intracellular pathogenesis-related protein in rice. Plant Cell Physiol. 37:9-18.

Mitchell, H. J., Hall, S. A., Stratford, R., Hall, J. L., and Barber, M. S. 1999. Differential induction of cinnamyl alcohol dehydrogenase during defensive lignification in wheat (Triticum aestivum L.): Characterisation of the major inducible form. Planta 208:31-37.

Moonil, K., Joon-Woo, A., Un-Ho, J., Doil, C., Kyung-Hee, P., and HyunSook, P. 2003. Activation of the programmed cell death pathway by inhibition of proteasome function in plants. J. Biol. Chem. 278:19406-19415.

Nakazono, M., Tsuji, H., Li, Y., Saisho, D., Arimura, S., Tsutsumi, N., and Hirai, A. 2000. Expression of a gene encoding mitochondrial aldehyde dehydrogenase in rice increases under submerged conditions. Plant Physiol. 124:587-598.

Nandi, A., Krothapalli, K., Buseman, C., Li, M., Welti, R., Enyedi, A., and Shah, J. 2003. Arabidopsis sfd mutants affect plastidic lipid composition and suppress dwarfing, cell death, and the enhanced disease resistance phenotypes resulting from the deficiency of a fatty acid desaturase. Plant Cell 15:2383-2398.

Peck, S. C., Nuhse, T. S., Hess, D., Iglesias, A., Meins, F., and Boller, T. 2001. Directed proteomics identifies a plant-specific protein rapidly phosphorylated in response to bacterial and fungal elicitors. Plant Cell 13:1467-1475.

Pellegrini, L., Geoffroy, P., Fritig, B., and Legrand, M. 1993. Molecular cloning and expression of a new class of ortho-diphenol- $O$-methyltransferases induced in tobacco (Nicotiana tabacum L.) leaves by infection or elicitor treatment. Plant Physiol. 103:509-517.

Pellegrini, L., Rohfritsch, O., Fritig, B., and Legrand, M. 1994. Phenylalanine ammonia-lyase in tobacco (Molecular cloning and gene expres- 
sion during the hypersensitive reaction to Tobacco mosaic virus and the response to a fungal elicitor). Plant Physiol. 106:877-886.

Perkins, D. N., Pappin, D. J., Creasy, D. M., and Cottrell, J. S. 1999. Probability-based protein identification by searching sequence databases using mass spectrometry data. Electrophoresis 20:3551-3567.

Pilloff, R. K., Devadas, S. K., Enyedi, A., and Raina, R. 2002. The Arabidopsis gain-of-function mutant dll1 spontaneously develops lesions mimicking cell death associated with disease. Plant J. 30:61-70.

Pontier, D., Balague, C., and Roby, D. 1998. The hypersensitive response. A programmed cell death associated with plant resistance. Comptes Rendus de l'Academie des Sciences, Series III. Sciences de la Vie 321:721-734.

Seo, S., Okamoto, M., Iwai, T., Iwano, M., Fukui, K., Isogai, A., Nakajima, N., and Ohashi, Y. 2000. Reduced levels of chloroplast FtsH protein in tobacco mosaic virus-infected tobacco leaves accelerate the hypersensitive reaction. Plant Cell 12:917-932.

Simmons, C., Hantke, S., Grant, S., Johal, G. S., and Briggs, S. P. 1998. The maize lethal leaf spot 1 mutant has elevated resistance to fungal infection at the leaf epidermis. Mol. Plant-Microbe Interact. 11:1110-1118.

Sullivan, J., Shirasu, K., and Deng, X. 2003. The diverse roles of ubiquitin and the 26S proteasome in the life of plants. Nat. Rev. Genet. 4:948-958.

Sunkar, R., Bartels, D., and Kirch, H. 2003. Overexpression of a stressinducible aldehyde dehydrogenase gene from Arabidopsis thaliana in transgenic plants improves stress tolerance. Plant J. 35:452-464.
Takahashi, A., Kawasaki, T., Henmi, K., ShiI, K., Kodama, O., Satoh, H and Shimamoto, K. 1999. Lesion mimic mutants of rice with alterations in early signaling events of defense. Plant J. 17:535-545.

Takahashi, A., Kawasaki, T., Wong, H., Suharsono, U., Hirano, H., and Shimamoto, K. 2003. Hyperphosphorylation of a mitochondrial protein, prohibitin, is induced by calyculin $\mathrm{A}$ in a rice lesion-mimic mutant cdr1. Plant Physiol. 132:1861-1869.

Wang, K. L.-C., Li, H., and Ecker, J. R. 2002. Ethylene biosynthesis and signaling networks. Plant Cell 14:S131-151.

Wolter M. H. K., Salamini, F., Schulze-Lefert, P. 1993. The mlo resistance alleles to powdery mildew infection in barley trigger a developmentally controlled defence mimic phenotype. Mol. Gen. Genet. 239:122-128.

Yamanouchi, U., Yano, M., Lin, H., Ashikari, M., and Yamada, K. 2002. A rice spotted leaf gene, $\mathrm{Spl7}$, encodes a heat stress transcription factor protein. Proc. Natl. Acad. Sci. U.S.A. 99:7530-7535.

Yin, Z., Chen, J., Zeng, L., Goh, M., Leung, H., Khush, G. S., and Wang, G.-L. 2000. Characterizing rice lesion mimic mutants and identifying a mutant with broad-spectrum resistance to rice blast and bacterial blight. Mol. Plant-Microbe Interact. 13:869-876.

Zheng, B., Halperin, T., Hruskova-Heidingsfeldova, O., Adam, Z., and Clarke, A. K. 2002. Characterization of chloroplast Clp proteins in Arabidopsis: Localization, tissue specificity and stress responses. Physiologia Plantarum 114:92-101. 